\title{
The usable capacity of porous materials for hydrogen storage
}

\author{
Maurice Schlichtenmayer $^{1,2} \cdot$ Michael Hirscher $^{1}$
}

Received: 11 November 2015/Accepted: 14 November 2015/Published online: 14 March 2016

(C) The Author(s) 2016. This article is published with open access at Springerlink.com

\begin{abstract}
A large number of different porous materials has been investigated for their hydrogen uptake over a wide pressure range and at different temperature. From the absolute adsorption isotherms, the enthalpy of adsorption is evaluated for a wide range of surface coverage. The usable capacity, defined as the amount of hydrogen released between a maximum tank pressure and a minimum back pressure for a fuel cell, is analyzed for isothermal operation. The usable capacity as a function of temperature shows a maximum which defines the optimum operating temperature. This optimum operating temperature is higher for materials possessing a higher enthalpy of adsorption. However, the fraction of the hydrogen stored overall that can be released at the optimum operating temperature is higher for materials with a lower enthalpy of adsorption than for the ones with higher enthalpy.
\end{abstract}

\section{Introduction}

In 2014 Hyundai started leasing the first fuel cell vehicle to customers followed in 2015 by the Mirai from Toyota. The hydrogen storage in both vehicles is based on 70-MPa highpressure vessels which require expensive carbon fibers. A

Electronic supplementary material The online version of this article (doi:10.1007/s00339-016-9864-6) contains supplementary material, which is available to authorized users.

Michael Hirscher

hirscher@mf.mpg.de; hirscher@is.mpg.de

1 Max Planck Institute for Intelligent Systems, Heisenbergstr. 3, 70569 Stuttgart, Germany

2 Present Address: ESK GmbH, Freiberg, Germany reduction in the storage pressure would reduce the cost for the next generation of fuel cell vehicles and for high compression at the refueling station. An alternative to high-pressure tanks is storage by physisorption in porous materials at more moderate temperatures and pressures. The high gravimetric storage capacity and low heat evolution during loading of porous metal-organic frameworks represents a huge step forward to materials for hydrogen storage systems based on cryo-adsorption. For material development the focus is on increasing the surface area or micropore volume and on increasing the adsorption enthalpy to obtain large storage capacities at moderate temperature. For technical application, the amount of hydrogen that can be reversibly released upon pressure reduction is a key value. In typical tank systems the pressure can only be reduced down to the back pressure of the fuel cell. Thus, the usable capacity is defined as the amount of hydrogen released from a material upon pressure reduction from a given maximum tank pressure to the fuel cell back pressure. As a typical operation mode, the isothermal operation is considered here. In literature, typically the overall hydrogen uptake starting from vacuum conditions is considered and it is often concluded that a high enthalpy of adsorption would be beneficial to reach high storage capacities at room temperature. However, the usable capacity as a function of operating temperature has not been evaluated until present. In this paper we experimentally determined the hydrogen uptake of 12 porous materials possessing different enthalpies of adsorption and evaluated the usable capacity at different operating temperatures.

\section{Fundamentals}

Hydrogen molecules can interact with solids by the socalled Van der Waals interaction establishing a weak bond between the hydrogen and the solid surface. This binding is 
called adsorption or physisorption and typically possesses an interaction enthalpy in the order of $3-10 \mathrm{~kJ} / \mathrm{mol}$. Materials can be optimized for the storage of hydrogen by selecting structures with an ideal enthalpy of adsorption and by offering more surface for the adsorption of hydrogen. Nowadays, the materials with the highest hydrogen uptakes are so-called metal-organic frameworks (MOFs), which are highly porous structures with specific surface areas up to $6200 \mathrm{~m}^{2} / \mathrm{g}$ and micropore volumes up to $3.6 \mathrm{~cm}^{3} / \mathrm{g}[1,2]$.

Since the enthalpy of adsorption is weak compared to the kinetic energy of the molecules at ambient conditions, a significant adsorption only takes place at elevated pressure and low temperature. In this work, most measurements are carried out at pressures up to $2.5 \mathrm{MPa}$ and temperatures down to $77 \mathrm{~K}$. The most prominent methods for measuring hydrogen adsorption (volumetric by Sieverts-type instruments or gravimetry by microbalances) both determine the excess uptake. It quantifies the amount of hydrogen in a material exceeding the amount of gas present in the pores without any gas-solid interaction (the latter being typically measured with helium, since it exhibits the weakest gassolid interaction of all gases) under the same pressure and temperature conditions (see Fig. 1).

Some theoretical models describe the amount of hydrogen in the adsorbed layer on the material surface, which is not correctly quantified by the excess uptake,

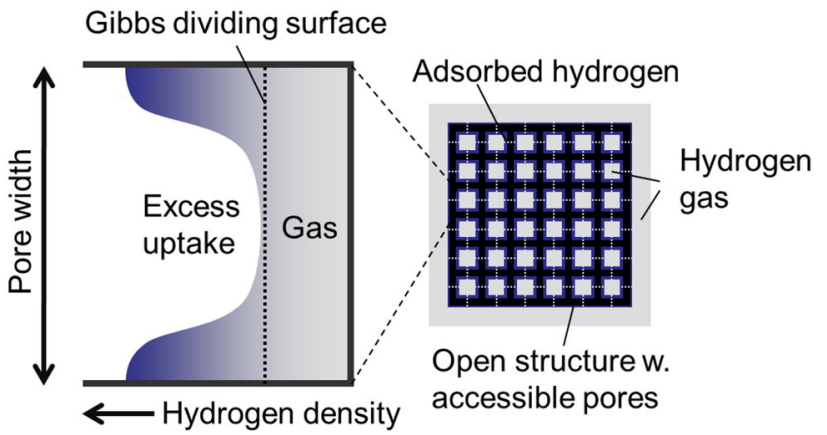

Fig. 1 Schematic representation of a porous material and the hydrogen distribution within a single pore. Due to the Van der Waals interaction, the hydrogen density at the pore walls is higher than in the center of the pores. The easiest way to measure the adsorbed amount of hydrogen at a defined pressure and temperature is by measuring the complete amount of hydrogen present in a sample cell and subtracting the expected amount of hydrogen gas. In the picture above, this corresponds to an integration of the hydrogen left of the indicated Gibbs dividing surface. The resulting amount of hydrogen is called excess uptake. However, this does not correctly represent the amount of hydrogen bound by van der Waals interaction, since it does not account for the hydrogen in contact with the material surface, which is right of the Gibbs dividing surface (the gas density contribution to the molecules in the adsorbed layer). Using a correction factor (see Eq. 1) the absolute uptake can be calculated, which accounts for all hydrogen in the adsorbed layer on the surface of the material especially at high pressure. A correction factor can be employed to calculate the so-called absolute uptake accounting for the different high-pressure behavior:

$n_{\mathrm{abs}}=n_{\mathrm{exc}}\left(1-\frac{p M}{\rho_{\mathrm{ads}} R T}\right)^{-1}$

Here, $n_{\text {abs }}$ and $n_{\text {exc }}$ denote the absolute and the excess uptake, respectively, and $p, M, \rho_{\text {ads }}, R$ and $T$ are the gas pressure, the molar mass of the gas particles, the density of the adsorbed phase, the gas constant and the temperature. Usually, the density of the adsorbed phase is identified with the liquid density at ambient pressure $(0.07 \mathrm{~g} / \mathrm{ml})$; however, some measurements indicate a slightly lower [3] or even higher value $[4,5]$.

Another important quantity for real tank applications is the total uptake, which includes all hydrogen present in a material regardless, whether it is in an adsorbed state or in the gas state. After an independent measurement of both packing density $\rho_{\text {pack }}$ and skeleton density $\rho_{\text {skel }}$, it can be derived from the excess uptake:

$n_{\text {tot }}=n_{\text {exc }}+\left(\frac{1}{\rho_{\text {pack }}}-\frac{1}{\rho_{\text {skel }}}\right) \frac{p M}{Z R T}$

For given hydrogen uptake (or surface coverage) $\Gamma$ the enthalpy of adsorption $\Delta h$ is obtained from a set of absolute uptake measurements using the van t' Hoff equation:

$\left.\frac{\partial \ln p / p_{0}}{\partial 1 / T}\right|_{\Gamma}=\frac{\Delta h}{R}$

As defined above, the enthalpy is always negative. In this work, however, for simplicity only the positive value is stated.

For the application in hydrogen adsorption tanks, the porous material should be able to adsorb and also to release as much hydrogen as possible at defined operating conditions. These conditions are given by the maximum allowed tank pressure $p_{\text {max }}$, by the back pressure $p_{\text {back }}$, which is required from the hydrogen consumer, typically a fuel cell, and by the tank temperature $T$. In order to evaluate the effect of operating conditions and enthalpy of adsorption quantitatively, the so-called usable capacity $u$ is defined:

$u\left(p_{\text {max }}, p_{\text {back }}, T\right)=n_{\text {abs }}\left(p_{\text {max }}, T\right)-n_{\text {abs }}\left(p_{\text {back }}, T\right)$

The usable capacity of a material at given maximum pressure and back pressure can be plotted as a function of the operating temperature (see Fig. 2, panel (c)). In such plots the usable capacity has the shape of a broad peak. This is because regardless of the pressure at low enough temperature the surface is saturated with hydrogen and at high enough temperature the uptake is very small. The temperature, where the maximum usable capacity can be 

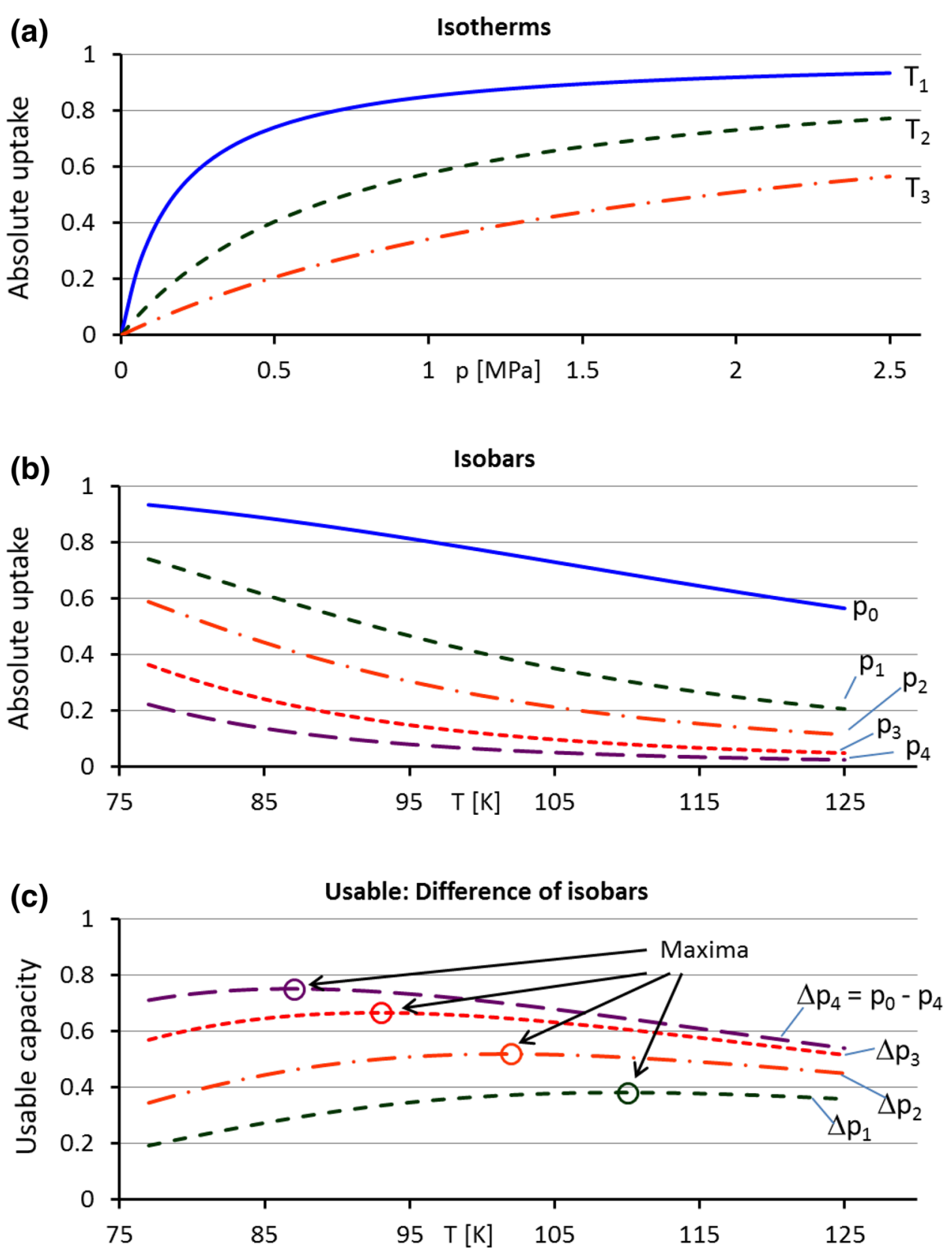

Fig. 2 Derivation scheme of the usable capacity for an idealized material with type I isotherms. All uptakes shown are normalized to the so-called saturation uptake. The top a shows isotherms at three different temperatures, as they are usually measured experimentally. In the case of pure physisorption by Van der Waals forces the isotherms are strictly concave with a steep inclination at low pressure, approaching a saturation value at high pressure. From a larger set of isotherms at different temperatures, it is possible to construct isobars as shown in (b). These isobars exhibit a reverse s-shape of which in (b) only sections can be seen. For falling temperatures, all isobars converge to the saturation uptake the faster the higher the specific

released, is called optimum operating temperature $T_{\text {opt }}$. The occurrence of such maxima of the usable capacity was confirmed in several publications [6-8]. pressure. For rising temperatures, all isobars approach zero, while low-pressure isobars decline faster than high-pressure isobars. The usable capacity of a material is the amount of hydrogen that is released upon a given pressure drop. It also is a function of the temperature, and therefore, for a given start and end, pressure can be plotted as the difference of both these isobars (see c). Since for high and low temperatures, all isobars converge to the same value the usable capacity must approach zero at high and low temperatures, and consequently, it must show a maximum at some temperature in between, which is called the optimum operating temperature

The materials investigated in this work have been selected to cover the range of typical properties for porous materials for hydrogen storage. They possess specific 
surface areas between 350 and $5000 \mathrm{~m}^{2} / \mathrm{g}$ and pore sizes in the range from 0.34 to $2.6 \mathrm{~nm}$. Different chemical structures like activated carbons, MOFs, also aerogels, and crystalline carbon structures are included. In particular the MOFs exhibit a great variation of chemical compositions and structures themselves, as they are built out of many different types of metals centers and possess channel-like pores as well as spherical pores. Some MOFs consist of only one type of pore, while others are built out of two or three types of pores being connected to a three-dimensional structure. A summary of the materials and further references are given in Table 1.

It has been reported previously that the chemical composition and the structure of the materials are of less relevance to their adsorption behavior at high pressure; instead, material properties like surface area or pore size distribution govern the hydrogen uptake. The saturation uptake was found to be proportional to the specific surface area $[9,10]$ and to the micropore volume [10-12]. The pore diameter seems to have a strong influence on the average enthalpy of adsorption [13-15], which in turn determines the temperature dependence of the hydrogen uptake. Nevertheless, in this work a great variety of different structures is evaluated for making sure that the results about the usable capacity are representative for all materials.

\section{Experimental method}

Prior to all measurements the samples have been activated by evacuation at $10^{-4} \mathrm{~Pa}$ for at least $12 \mathrm{~h}$ at elevated temperature (Table 1). Typical sample masses are in the order of $100 \mathrm{mg}$. For further characterization the specific surface area of all materials has been measured using nitrogen adsorption at $77 \mathrm{~K}$ according to the BET method (pressure region: $0.02<p / p_{0}<0.2$ ). Additionally, the packing density is required for the calculation of the volumetric capacities. It is obtained by slightly compacting the samples in the sample holder (by tapping the sample holder) and measuring the calibrated filling level.

\section{Hydrogen uptake measurements}

The hydrogen uptake of the materials was measured volumetrically using a fully automated Sieverts-type apparatus (PCT-Pro 2000 with microdoser, Setaram [16]). The underlying principle of the volumetric method is the measurement of the expansion of gas from a calibrated reservoir volume into the sample cell. The instrument used here has a sample cell of $1.274 \mathrm{ml}$ and a reservoir volume of $0.517 \mathrm{ml}$. The sample cell can be submerged in liquid nitrogen or liquid argon. Alternatively, a self-built cryostat can be used to control the sample temperature between $83 \mathrm{~K}$ and $135 \mathrm{~K}$. Additionally, the skeleton density of the materials was measured by helium pycnometry at room temperature up to $0.4 \mathrm{MPa}$. The hydrogen adsorption measurement at cryogenic temperatures always involves a temperature gradient between the pressure transducer and the sample cell. For correcting the effect of the temperature gradient reference measurements using non-adsorbing reference samples have been made in the whole temperature and pressure range (see supporting information). With this technique the hydrogen uptake of 12 samples with different

Table 1 Characterization results for all materials consisting of specific surface area, densities, and hydrogen excess uptake at $77 \mathrm{~K}$ and $2.5 \mathrm{MPa}$

\begin{tabular}{|c|c|c|c|c|c|}
\hline Material & $\begin{array}{l}\mathrm{SSA} \\
\left(\mathrm{m}^{2} / \mathrm{g}\right)\end{array}$ & $\begin{array}{l}\text { Skeleton density } \\
(\mathrm{g} / \mathrm{ml})\end{array}$ & $\begin{array}{l}\text { Packing density } \\
(\mathrm{g} / \mathrm{ml})\end{array}$ & $\begin{array}{l}\mathrm{H}_{2} \text { excess uptake } \\
(77 \mathrm{~K}, 2.5 \mathrm{MPa})[\mathrm{mg} / \mathrm{g}]\end{array}$ & $\begin{array}{l}\text { Synthesis and } \\
\text { structure }\end{array}$ \\
\hline AX-21_33 (activated carbon) & 3336 & 2.21 & 0.264 & 57.1 & \\
\hline PAF-1 & 3363 & 1.12 & 0.138 & 63.5 & [19] \\
\hline DUT-6 & 4414 & 1.66 & 0.228 & 61.6 & {$[20]$} \\
\hline DUT-8 (Co) & 664 & 1.52 & 0.294 & 11.6 & {$[21]$} \\
\hline DUT-8 $(\mathrm{Cu})$ & 2117 & 1.70 & 0.283 & 50.1 & {$[21]$} \\
\hline DUT-9 & 3293 & 1.44 & 0.265 & 55.3 & {$[22]$} \\
\hline DUT-23 (Co) & 4850 & 1.42 & 0.229 & 72.1 & {$[23]$} \\
\hline MFU-4 (Co) & $1350^{\mathrm{a}}$ & 1.93 & 0.441 & 29.3 & {$[24]$} \\
\hline $\mathrm{Mg}$ formate & 357 & 1.68 & 0.594 & 6.8 & {$[25]$} \\
\hline MIL-100 (Fe) & 1677 & 2.03 & 0.427 & 27.9 & {$[26]$} \\
\hline MOF-177 & 4239 & 1.39 & 0.261 & $67.0^{\mathrm{b}}$ & {$[27]$} \\
\hline Fe-BTC-Gel (xerogel) & 772 & 1.81 & 0.693 & 16.5 & [28] \\
\hline
\end{tabular}

Additionally, references regarding the material synthesis are given

${ }^{\text {a }}$ Specific surface area of the Zn compound [18]

${ }^{b}$ Measured at $2 \mathrm{MPa}$ 
structure and chemical composition was measured at seven different temperatures between 77 and $125 \mathrm{~K}$ up to $2.5 \mathrm{MPa}$.

\section{Results}

The isotherms measured at a temperature of $77 \mathrm{~K}$ are summarized in Figs. 3, 4, 5, 6, and 7 (see supporting information for hydrogen adsorption isotherms at different temperatures). For all materials the hydrogen uptake was fully reversible and all isotherms showed a typical IUPAC type I behavior (Fig. 3). A summary of the excess uptake of all materials is given in Table 1. The uptakes measured correspond well with the specific surface areas of the materials according to the rule of thumb that for $500 \mathrm{~m}^{2} / \mathrm{g}$ of specific surface area a hydrogen uptake of $10 \mathrm{mg} / \mathrm{g}$ (approximately $1 \mathrm{wt} \%$ ) can be expected [9, 10]. For the material MOF-177, which is a well-established benchmark material, the excess uptake of $67.0 \mathrm{mg} / \mathrm{g}(6.28 \mathrm{wt} \%)$ at $2 \mathrm{MPa}$ and $77 \mathrm{~K}$ is in good agreement with literature values [17].

The absolute uptake was calculated for all materials at all pressures and temperatures (Fig. 4). Generally, the isotherms of the absolute uptake converge to the saturation uptake and do not show a decrease after reaching a maximum value. This behavior can be observed by comparing the excess and the absolute isotherms of $\mathrm{Mg}$ formate. All further calculations and discussions of the usable capacity are based on the absolute uptake of the materials, since this best characterizes the amount of hydrogen in the adsorbed layer.
Figure 5 gives an enlarged view of the low-pressure region $(<0.5 \mathrm{MPa})$ of Fig. 4. This is of special interest for assessing the usable capacity of the materials, since the back pressure of most hydrogen systems typically lies within this region. Especially for materials like AX-21_33, MFU-4(Co), Fe-BTC-Gel, or Mg formate, which possess a high uptake already at low pressure, the amount of hydrogen remaining adsorbed in the material at the back pressure clearly limits the usable capacity of these materials.

The initial inclination of the isotherms at low pressure is directly connected to the so-called enthalpy of adsorption. A high enthalpy leads to a strong initial increase in the isotherms, since the hydrogen molecules interact strongly with the material. The uptake of such materials gets close to the saturation uptake already at low pressure, so their isotherms show a distinctive knee in contrast to materials with low adsorption enthalpy, whose isotherms show a more continuous increase.

The packing density and the skeleton density are both determined as described above. They allow the calculation of the accessible pore volume (including interparticle void space) and of the total hydrogen uptake, which is the relevant quantity for the application in an adsorption tank. In Fig. 6 the total uptake at $77 \mathrm{~K}$ is shown for all measured materials on a gravimetric basis. It is especially high (up to $112 \mathrm{mg} / \mathrm{g}$ ) for PAF-1 due to its high porosity.

In addition to the total gravimetric uptake, the total volumetric uptake is a very important quantity for the final design of the storage vessel. The total volumetric uptake is given in Fig. 7 for a temperature of $77 \mathrm{~K}$. The highest total
Fig. 3 Isotherms of the excess hydrogen uptake at $77 \mathrm{~K}$ for all materials. Each isotherm exhibits a typical IUPAC type I form with a steep initial increase getting flatter at higher pressure

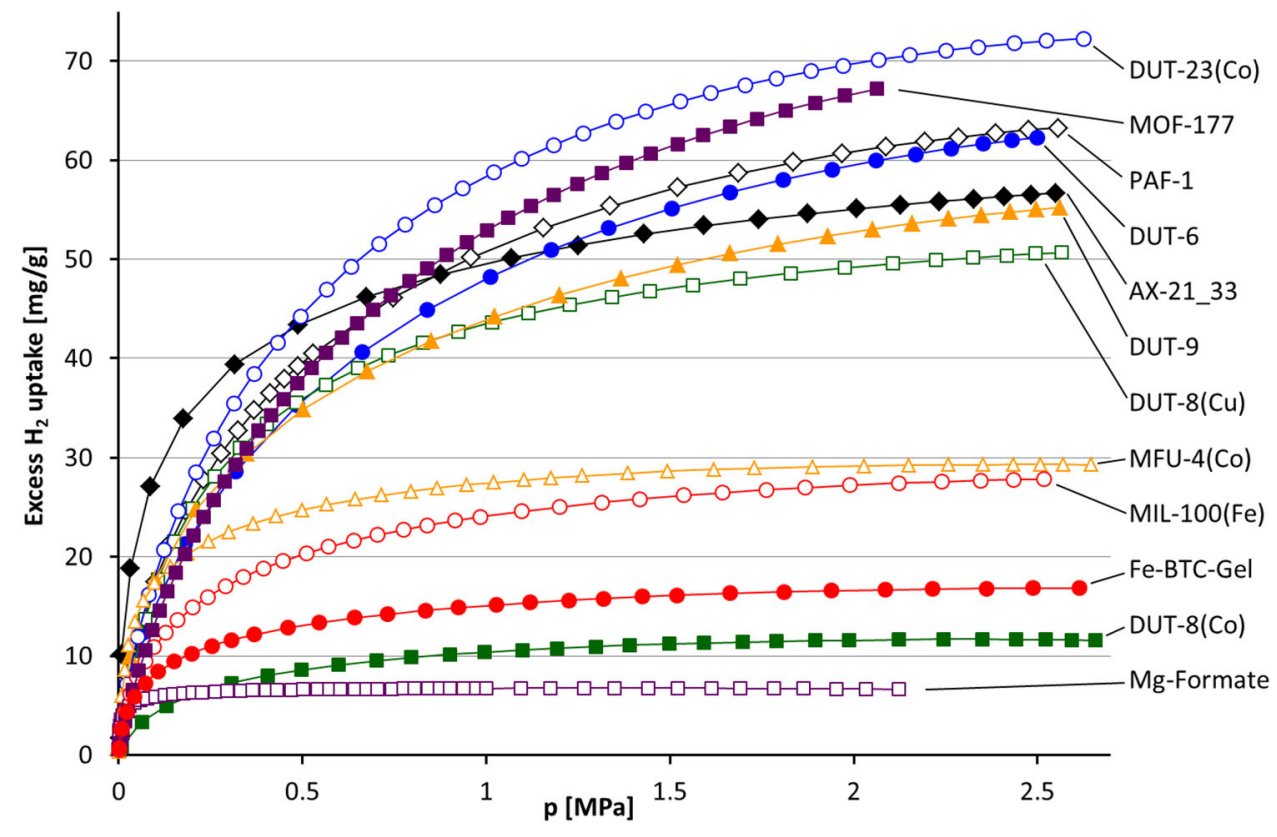



absolute hydrogen uptake at $77 \mathrm{~K}$ for all materials. In contrast to the excess uptake saturation uptake and never show a negative inclination
Fig. 4 Isotherms of the these isotherms converge to the

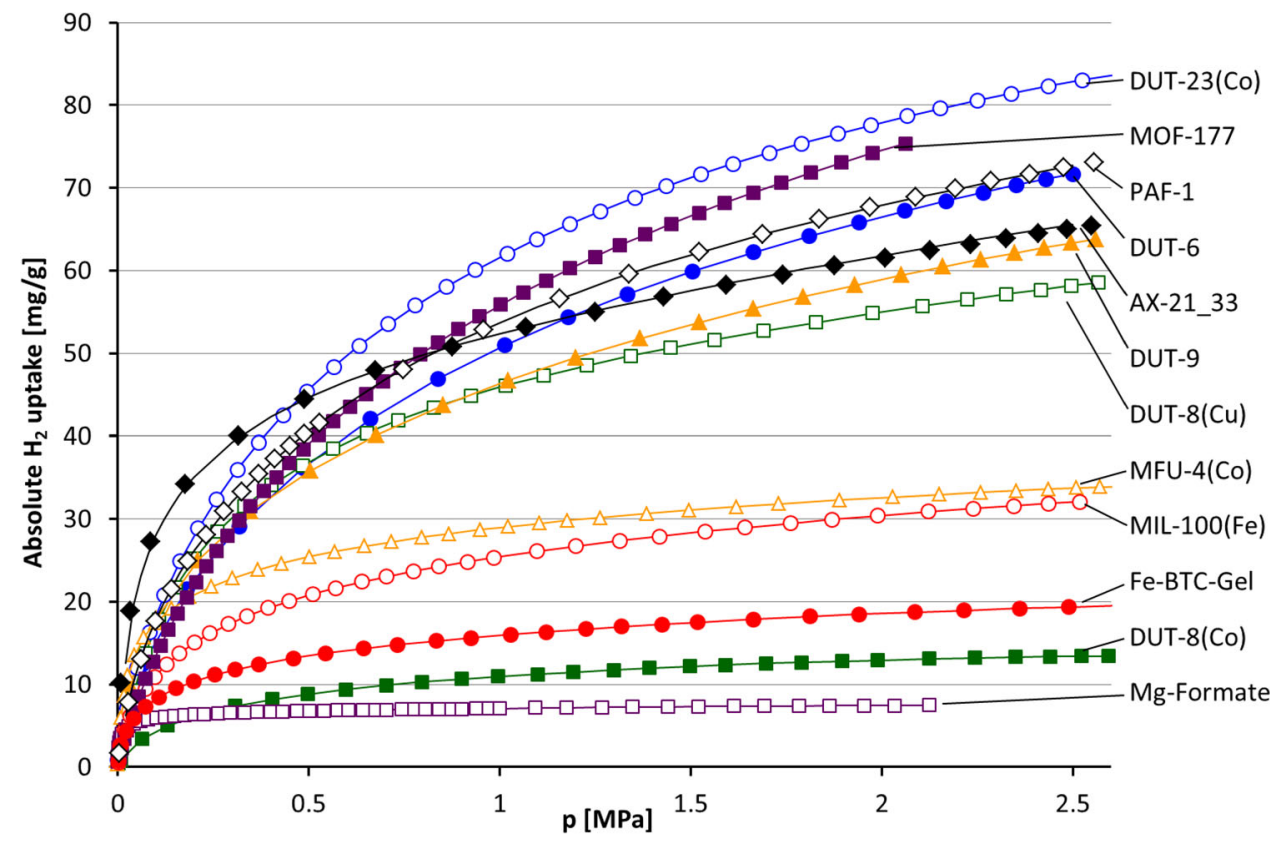

Fig. 5 Enlarged view of the absolute hydrogen uptake at $77 \mathrm{~K}$ in the pressure range from 0 to $0.5 \mathrm{MPa}$, which is the typical pressure range for the back pressure required by hydrogen consuming units like fuel cells. The amount of hydrogen still adsorbed in the material at the specific back pressure of a system cannot be used but remains in the tank unless the tank is heated up or an extra pump is installed

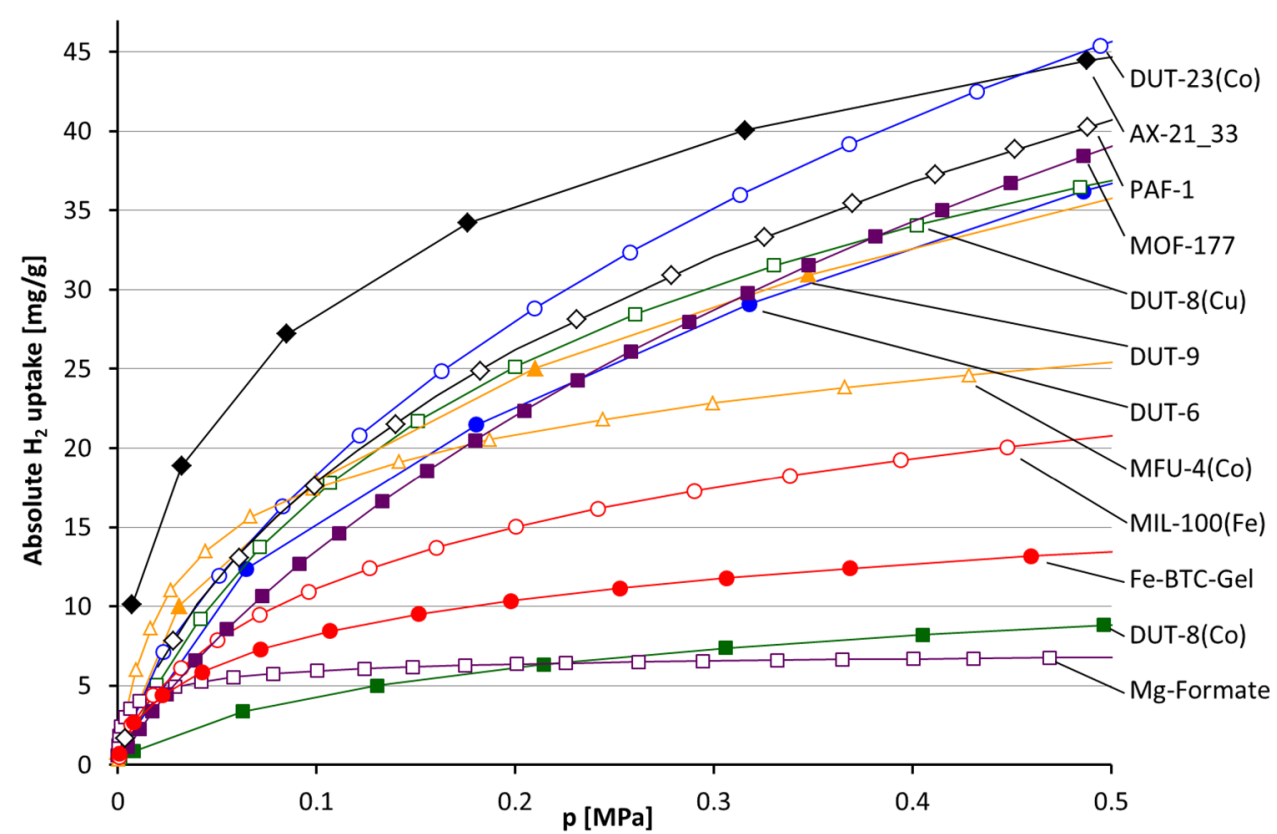

volumetric uptake is measured for the activated carbon AX-21_33 and the MOFs DUT-23(Co) and MOF-177, all reaching more than $22 \mathrm{~g} / \mathrm{l}$ at pressures lower than $2.5 \mathrm{MPa}$. These materials possess both, an extraordinary high absolute uptake (quantifying their ability to adsorb hydrogen) and an at least average packing density, allowing a more compact storage of the hydrogen than in low-density materials like PAF-1. This shows that for hydrogen storage under these conditions the adsorbed hydrogen contributes more to the total volumetric uptake than the hydrogen gas in the pores. For example, a cryo-adsorption tank operating at $77 \mathrm{~K}$ with an inner volume of 2001 filled with MOF-177 could store $4.5 \mathrm{~kg}$ hydrogen at a pressure of $2 \mathrm{MPa}$, in contrast, a cryo-compressed hydrogen storage tank requires about $7 \mathrm{MPa}$ to achieve the same storage density at $77 \mathrm{~K}$.

The isosteric enthalpy of adsorption can be calculated using so-called van t' Hoff plots. For an easy comparison of the enthalpies of different materials with diverging saturation uptakes, they are often plotted versus the surface coverage. Based on the isotherms (absolute uptake) measured at seven different temperatures between 77 and $125 \mathrm{~K}$, the isosteric enthalpies of adsorption were 
Fig. 6 Total hydrogen uptake of all materials at $77 \mathrm{~K}$. In contrast to the excess and the absolute uptake, which both are different approaches to quantify the amount of hydrogen in the also includes the hydrogen gas in the pores and between the adsorbent particles. For assessing the amount of hydrogen, that can be stored in an adsorption tank, this is the relevant quantity adsorbed state, the total uptake

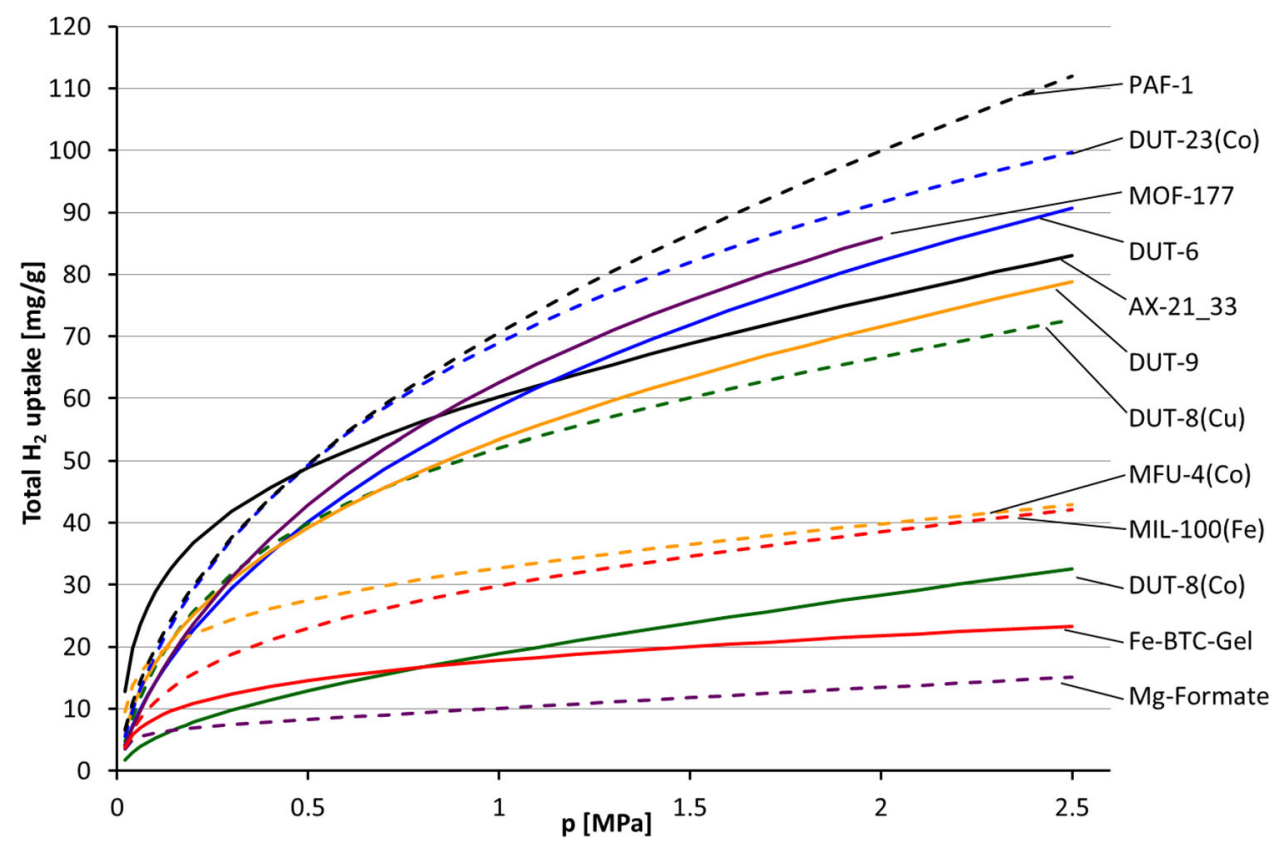

Fig. 7 Total hydrogen uptake of all materials at $77 \mathrm{~K}$ in volumetric units. It includes hydrogen gas in the pores and between the particles and is calculated using the measured packing densities. Since space is limited in hydrogen applications like fuel cell cars, the total volumetric uptake provides a useful measure to find an optimal material

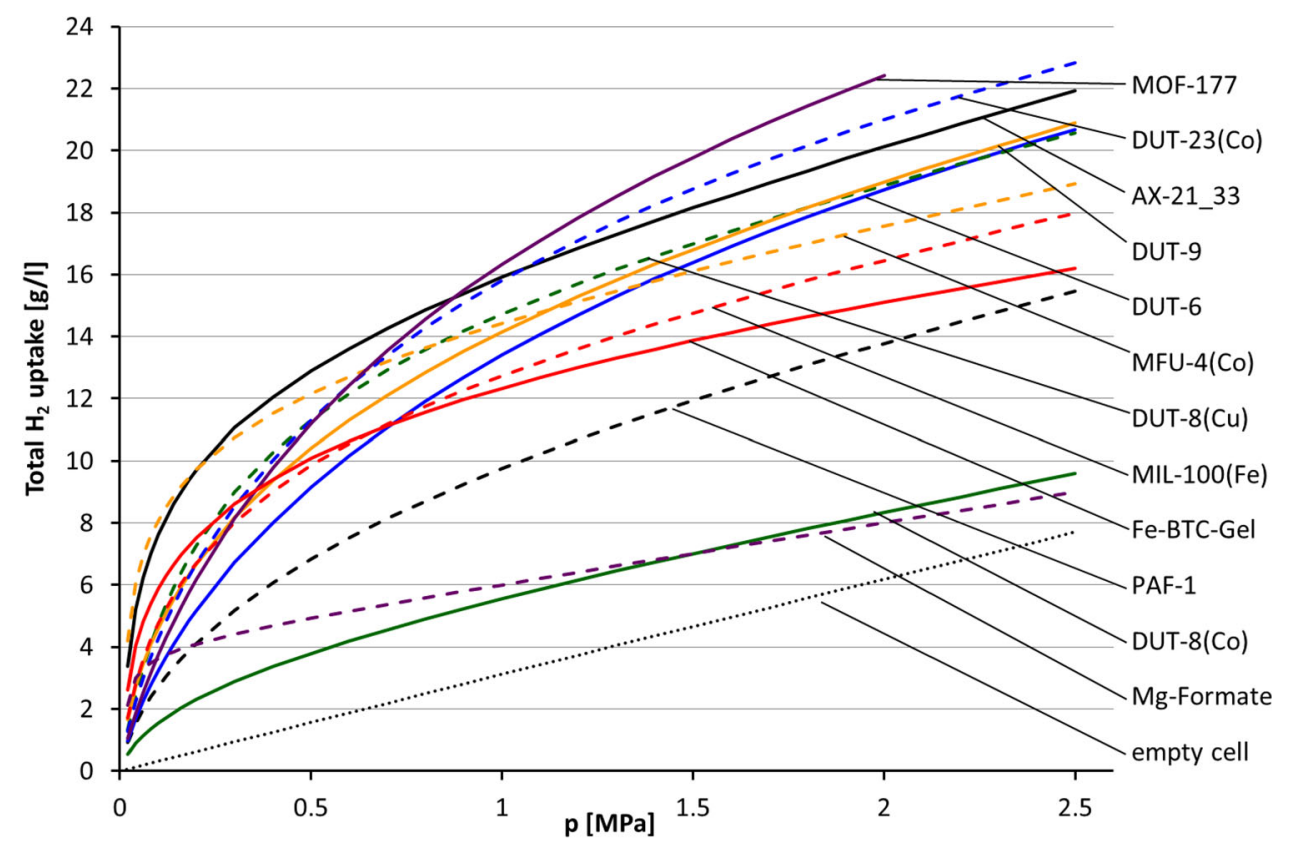

calculated over a wide range of surface coverage (typically 0.06-0.76, see Fig. 8 and supporting information) for all investigated materials. Furthermore, the average enthalpy of each material was calculated over this range and is stated in Table 2. Generally, all enthalpies are in the range from 3.5 to $8 \mathrm{~kJ} / \mathrm{mol}$, which is the typical range for physisorption, and for each material they decrease with rising coverage. This decrease results from the heterogeneity of the adsorption sites [29, 30], which are filled more or less successively from high-enthalpy to low-enthalpy sites.
For three selected materials (DUT-23(Co), Fe-BTC-Gel, and $\mathrm{Mg}$ formate) the enthalpy of adsorption is shown as a function of relative surface coverage in Fig. 8. Of these materials, DUT-23 exhibits the lowest enthalpy, starting at $4.2 \mathrm{~kJ} / \mathrm{mol}$ and decreasing almost linearly to $3.5 \mathrm{~kJ} / \mathrm{mol}$ with increasing coverage indicating that all adsorption sites possess a similar binding strength. According to the structural analysis DUT-23(Co) mainly possesses large pores of $2.4 \mathrm{~nm}$ diameter [23] resulting in a rather low enthalpy of adsorption [13]. In contrast to DUT-23(Co), Fe-BTC-Gel has an amorphous structure with pores mainly 
Fig. 8 Isosteric enthalpy of adsorption of the materials DUT-23(Co), Mg formate and Fe-BTC-Gel. The enthalpies lie in the range from 3.5 to $8 \mathrm{~kJ} / \mathrm{mol}$, which is typical for Van der Waals interactions. A decline of the enthalpy with higher surface coverage indicates that the material possesses different adsorption sites with different interaction strengths and that the stronger adsorption sites are filled first

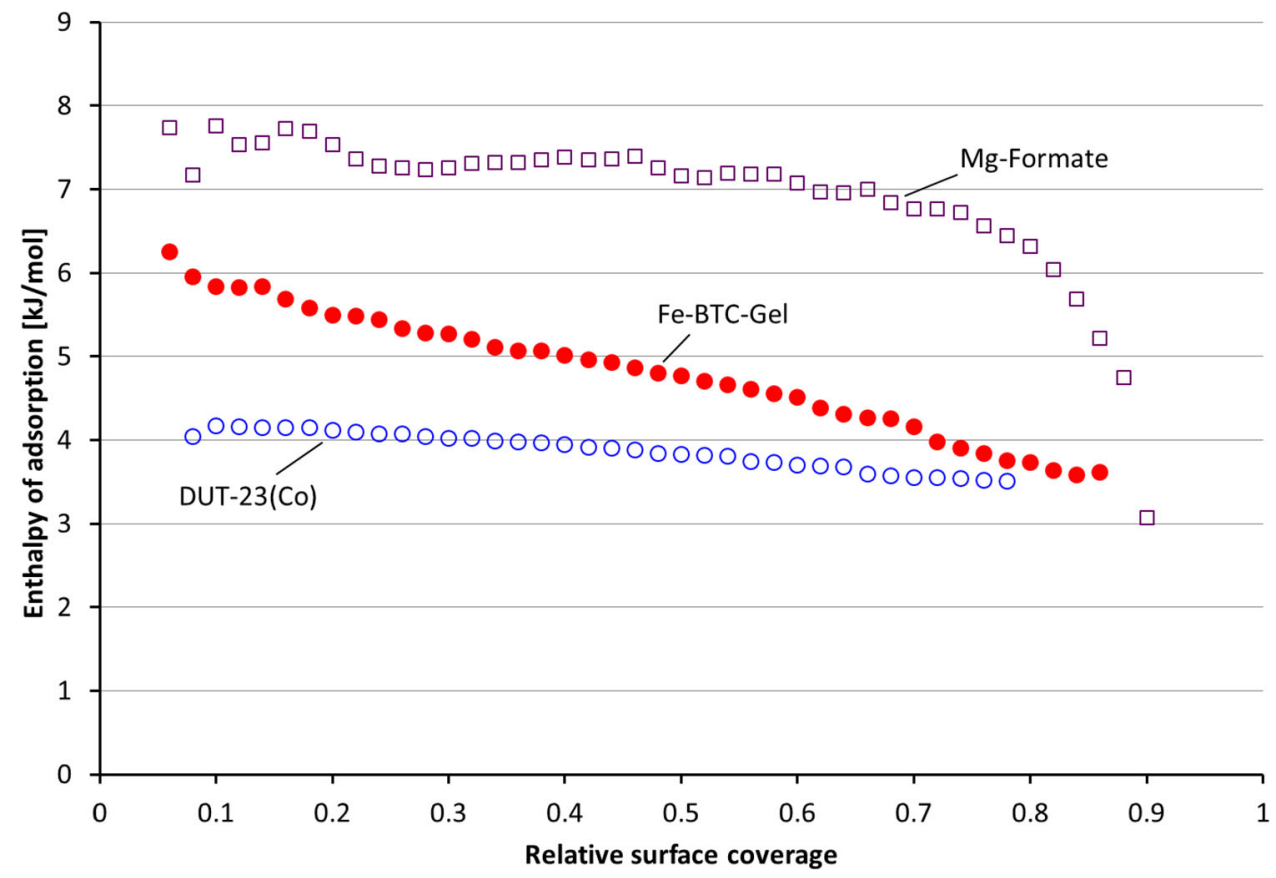

Table 2 Summary of results of hydrogen uptake measurements for all materials

\begin{tabular}{|c|c|c|c|c|c|}
\hline Material & $\begin{array}{l}\text { Absolute uptake (at } \\
2.5 \mathrm{MPa} \text { and } 77 \mathrm{~K}) \\
{[\mathrm{mg} / \mathrm{g}]}\end{array}$ & $\begin{array}{l}\text { Average enthalpy } \\
\text { of adsorption } \\
(\mathrm{kJ} / \mathrm{mol})\end{array}$ & $\begin{array}{l}\text { Optimum operating } \\
\text { temperature } T_{\mathrm{opt}}(2.5 \mathrm{MPa} \text { to } \\
0.2 \mathrm{MPa})[\mathrm{K}]\end{array}$ & $\begin{array}{l}\text { Usable capacity at } T_{\text {opt }} \\
(2.5 \mathrm{MPa} \text { to } 0.2 \mathrm{MPa}) \\
{[\mathrm{mg} / \mathrm{g}]}\end{array}$ & $\begin{array}{l}\text { Usable fraction } \\
(2.5 \mathrm{MPa} \text { to } \\
0.2 \mathrm{MPa})[\%]\end{array}$ \\
\hline $\begin{array}{l}\text { AX-21_33 } \\
\text { (activated } \\
\text { carbon) }\end{array}$ & 65.6 & 5.2 & 85 & 32.5 & 50 \\
\hline PAF-1 & 72.7 & 4.2 & $<77$ & 46.5 & 64 \\
\hline DUT-6 & 71.0 & 3.7 & $<77$ & 50.4 & 71 \\
\hline DUT-8(Co) & 13.3 & 4.5 & 89 & 8.2 & 62 \\
\hline DUT-8(Cu) & 57.6 & 4.9 & $<77$ & 33.4 & 58 \\
\hline DUT-9 & 63.5 & 4.3 & $<77$ & 40 & 63 \\
\hline DUT-23(Co) & 82.3 & 3.9 & $<77$ & 55 & 67 \\
\hline MFU-4(Co) & 33.9 & 4.7 & 98 & 14.6 & 43 \\
\hline $\mathrm{Mg}$ formate & 7.8 & 7.2 & 112 & 3.2 & 41 \\
\hline MIL-100(Fe) & 32.1 & 4.5 & 77 & 17.4 & 54 \\
\hline MOF- $177^{\mathrm{a}}$ & 74.5 & 3.7 & $<77$ & 52.5 & 70 \\
\hline $\begin{array}{l}\text { Fe-BTC-Gel } \\
\text { (xerogel) }\end{array}$ & 19.0 & 5.0 & 94 & 9.7 & 51 \\
\hline
\end{tabular}

The optimum operating temperature is where the usable capacity has its maximum. The usable fraction of a material is the usable capacity at $T_{\mathrm{opt}}$ normalized to its absolute uptake at $77 \mathrm{~K}$ and $2.5 \mathrm{MPa}$

${ }^{\text {a }}$ Maximum pressure for MOF-177 is $2 \mathrm{MPa}$

in the range below $5 \mathrm{~nm}$ [28] and shows an enthalpy of $6 \mathrm{~kJ} / \mathrm{mol}$ at low coverage decreasing strongly to $3.6 \mathrm{~kJ} / \mathrm{mol}$ at higher coverage. The third selected material, $\mathrm{Mg}$ formate, exhibits a high adsorption enthalpy of more than $7 \mathrm{~kJ} / \mathrm{mol}$ over a wide range of surface coverage, due to a narrow pore structure consisting of channels with an alternating diameter between 0.34 and $0.46 \mathrm{~nm}$ [15].

\section{Discussion}

During the past decade, many different MOFs have been investigated for their ability to store hydrogen and potential as storage systems for technical applications. The main focus of these studies has been an optimization regarding their specific surface area, micropore volume, and 
Fig. 9 Usable capacity of DUT-23(Co), Fe-BTC-Gel and $\mathrm{Mg}$ formate for an operating pressure range from 0.2 to $2.5 \mathrm{MPa}$. The graphs are generated in analogy to Fig. 2 from the full set of isotherms of a material (see supporting information). For Fe-BTC-Gel and $\mathrm{Mg}$ formate the usable capacity shows a maximum at a temperature of 94 and $112 \mathrm{~K}$, respectively. The maximum of DUT-23(Co) lies outside of the measured temperature range

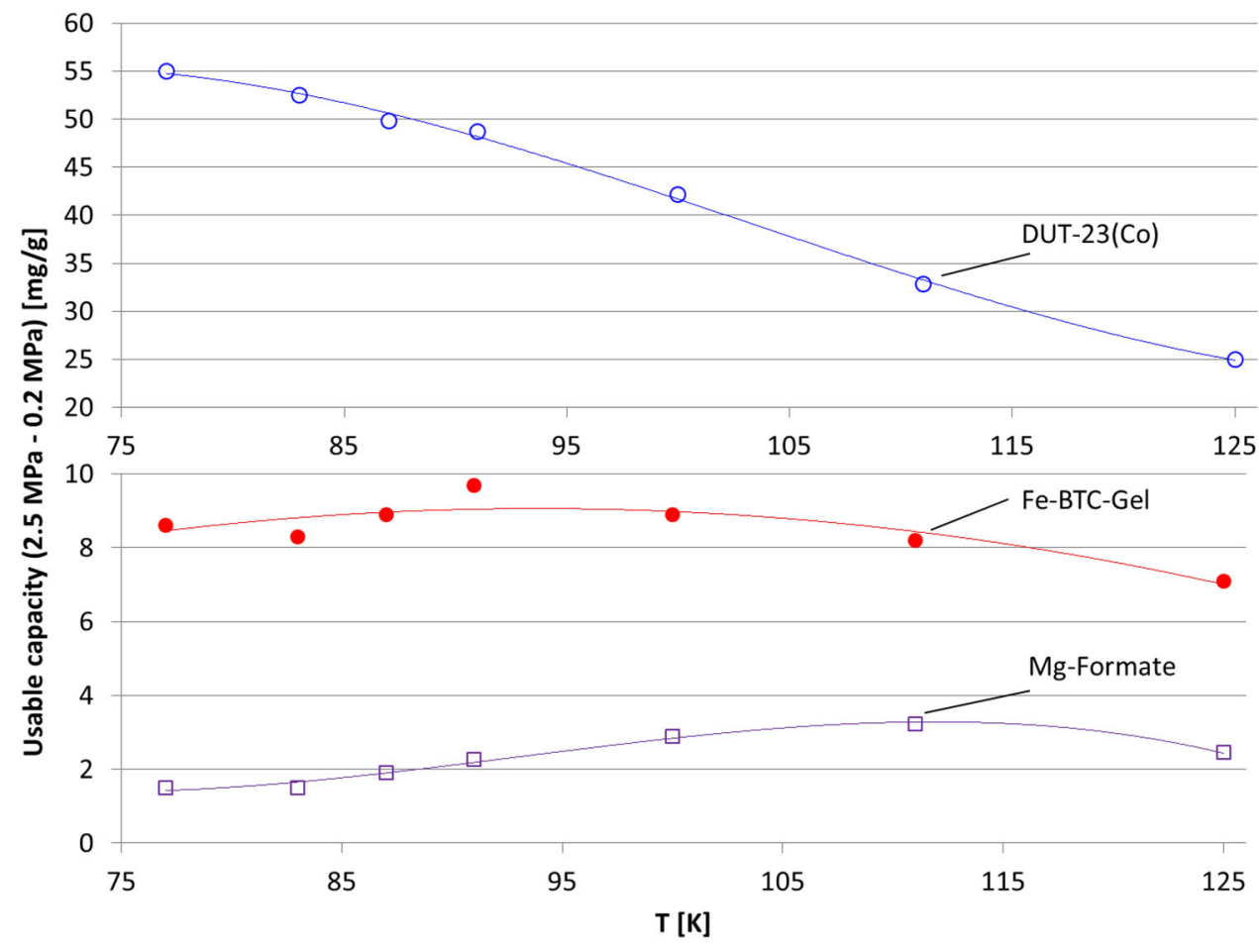

interaction strength. Generally, for a high uptake at elevated temperature a high enthalpy of adsorption is beneficial, as shown theoretically an activation enthalpy of adsorption around $20 \mathrm{~kJ} / \mathrm{mol}$ would be optimal for storage operation at room temperature $[6,7]$. However, for the use as a storage system in a fuel cell vehicle, the amount of hydrogen which can be delivered to the fuel cell is the key quantity. This usable capacity is defined at a given operating temperature as the amount released between the maximum tank pressure and the back pressure required to operate the fuel cell.

Based on our measurements of the absolute hydrogen adsorption isotherms at different temperatures, we analyzed the usable capacities for a maximum tank pressure of 2.5 MPa and a system back pressure of 0.2 MPa for all materials. The usable capacities can be plotted versus the temperature of the isotherm, i.e., the operating temperature in an isothermal use. Figure 9 shows this analysis for three selected materials, DUT-23(Co), Fe-BTC-Gel, and Mg formate representing materials with low, medium, and high enthalpies of adsorption, respectively (see supporting information for the other materials).

All usable capacities are in the range between 1.5 and $55 \mathrm{mg} / \mathrm{g}$ and, thus, are substantially lower than the maximum absolute uptakes starting from vacuum conditions. The usable capacity of $\mathrm{Mg}$ formate has a broad maximum of $3.2 \mathrm{mg} / \mathrm{g}$ at $112 \mathrm{~K}$ and falls down to $1.5 \mathrm{mg} / \mathrm{g}$ at $77 \mathrm{~K}$ and $2.5 \mathrm{mg} / \mathrm{g}$ at $125 \mathrm{~K}$, so $112 \mathrm{~K}$ is the optimum operating temperature for a tank filled with $\mathrm{Mg}$ formate operating between $2.5 \mathrm{MPa}$ maximum tank pressure and $0.2 \mathrm{MPa}$ system back pressure. A similarly shaped maximum is observed for the material Fe-BTC-Gel starting with a usable capacity of $8.6 \mathrm{mg} / \mathrm{g}$ at $77 \mathrm{~K}$, showing a broad maximum of $9.1 \mathrm{mg} / \mathrm{g}$ at $94 \mathrm{~K}$ and declining to $7.1 \mathrm{mg} / \mathrm{g}$ at $125 \mathrm{~K}$. The optimum operating temperature of Fe-BTC$\mathrm{Gel}$ is shifted to a lower temperature compared to $\mathrm{Mg}$ formate due to its lower enthalpy of adsorption. In contrast to these two materials, the usable capacity of DUT-23(Co) clearly does not possess a maximum in the measured temperature range and, instead, decreases from $55 \mathrm{mg} / \mathrm{g}$ at $77 \mathrm{~K}$ to $25 \mathrm{mg} / \mathrm{g}$ at $125 \mathrm{~K}$. However, the curve flattens at $77 \mathrm{~K}$ indicating that a maximum would be observed at slightly lower temperatures. DUT-23(Co) with the lowest enthalpy of the three selected materials shows consistently the lowest optimum operating temperature.

Typically, porous materials show a distribution of the enthalpy of adsorption due to a pore size distribution or different chemical composition of the internal surface. This distribution of adsorption enthalpies causes a further broadening of the maximum of the usable capacity, since then the usable capacity is a superposition for different enthalpies. Fe-BTC-Gel is an example for such a material with a wide enthalpy distribution and a very broad maximum of the usable capacity.

All other materials investigated (see supporting information) show the same behavior for the usable capacity as a function of the operating temperature, either with a maximum in the observed temperature range or with a 
Fig. 10 Plot of the usable fraction (usable capacity at the optimum operating temperature normalized to the uptake at $77 \mathrm{~K}$ and $2.5 \mathrm{MPa}$ ) of all materials versus their optimum operating temperature. The materials PAF-1, DUT-6, DUT8(Cu), DUT-9, DUT-23(Co), and MOF-177 are inserted at $77 \mathrm{~K}$, since their optimum temperature could not be identified within the measured temperature range. There is a clear trend that materials with high optimum operating temperatures possess a low usable fraction for hydrogen storage operation

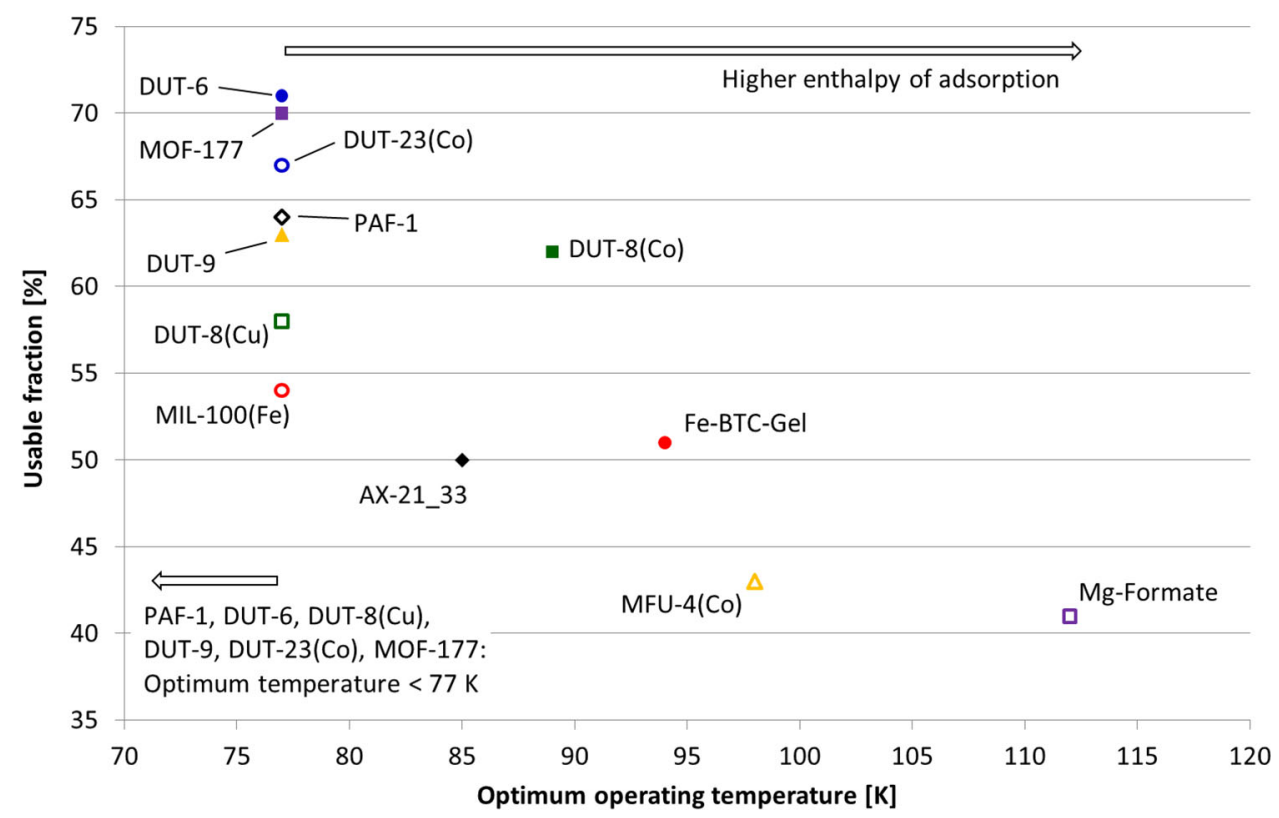

decreasing over the whole temperature range indicating that the maximum is below $77 \mathrm{~K}$. For all materials the optimum operating temperature and the usable capacity at this temperature are given in Table 2. An analysis using different operating pressure ranges yields similar results. The present results obtained on a wide basis of different porous materials confirm the occurrence of maxima of the usable capacity for any material and the correlation between the optimum operating temperature and the enthalpy of adsorption reported previously [6-8]. Furthermore, it can be concluded that for hydrogen storage in the pressure range between 2.5 and $0.2 \mathrm{MPa}$ for typical physisorption materials with an enthalpy in the order of $4 \mathrm{~kJ} / \mathrm{mol}$, the optimum temperature for the operation of a storage tank system will be around $80 \mathrm{~K}$. Lower operating temperatures will decrease the usable capacity more, since hydrogen will remain adsorbed on the surface of the material at the back pressure of the fuel cell.

For a further comparison of the different materials, we introduce the usable fraction in percent, which is defined as the usable capacity at the optimum operating temperature normalized by the overall absolute uptake at $2.5 \mathrm{MPa}$ and $77 \mathrm{~K}$. In Fig. 10 the usable fraction is plotted versus the optimum operating temperature. The measurement range in this work is limited to $77 \mathrm{~K}$, thus, materials with a lower optimum temperature are inserted at $77 \mathrm{~K}$ and their usable fraction is calculated from the usable capacity at $77 \mathrm{~K}$. Therefore, in Fig. 10 these materials would be shifted to lower temperatures and higher usable fractions if the range of measurement would be extended to even lower temperatures. For a material with a low average enthalpy of adsorption like DUT- 6 or MOF-177, more than $70 \%$ of the absolute hydrogen uptake can be released at $77 \mathrm{~K}$ and
0.2 MPa. However, for high-enthalpy materials like $\mathrm{Mg}$ formate, a usable fraction of only $40 \%$ can be delivered at the optimum operating temperature. A general trend is that materials with higher enthalpy of adsorption show a higher optimum operating temperature but can only deliver a lower usable fraction. Therefore, considering the usable capacity at the optimum operating temperature, and not as reported commonly the absolute uptake between vacuum and the maximum pressure, materials with a low enthalpy of adsorption can deliver a higher fraction of the stored hydrogen to the fuel cell than materials with higher enthalpy.

\section{Conclusion and outlook}

The usable capacity, i.e., the amount of hydrogen that can be released at a certain operating temperature between the maximum tank pressure and the back pressure required for the fuel cell, is the key value for technical application in a fuel cell vehicle. For different porous materials possessing high surface areas, the absolute hydrogen uptake is experimentally investigated as a function of temperature and pressure. This allows determining the usable capacity as a function of operating temperature in an isothermal operation of a storage system. The usable capacity shows a maximum at an optimum operating temperature which is at higher temperature for materials with higher enthalpy of adsorption. The fraction of the total hydrogen stored that can be released at the optimum operating temperature is higher for materials with lower enthalpy of adsorption than for those with higher enthalpy.

These results obtained for 12 different porous materials are valid for all physisorption materials showing a type I adsorption isotherm. Basically, almost all porous materials, 
including activated carbons, zeolites, MOFs, COFs, and other frameworks, show type I isotherms for hydrogen, and therefore, the present results are very important for selecting materials and defining their operation temperature in a real storage system.

Future developments could focus on materials showing different types of adsorption isotherms which may possibly increase in the usable capacity. One approach is the development of materials possessing a flexible structure, and therefore a shift of the initial uptake of the isotherm to higher pressure, i.e., a gating effect will occur, for example see [31]. Newest results on flexible MOFs for methane storage illustrate this idea further [32]. The field of flexible framework materials is just emerging, and no measurements for hydrogen over a wide pressure and temperature range are known so far.

Acknowledgments Partial funding by the European Hy-Co program financed by the German Federal Ministry of Economics and Technology (BMWi) is gratefully acknowledged. We further thank Stefan Kaskel, TU Dresden, Germany, Ulrich Müller, BASF SE, Ludwigshafen, Germany, Channing Ahn, CALTECH, Pasadena, CA, USA, and Dirk Volkmer, University of Augsburg, Germany, for providing the samples.

Open Access This article is distributed under the terms of the Creative Commons Attribution 4.0 International License (http://crea tivecommons.org/licenses/by/4.0/), which permits unrestricted use, distribution, and reproduction in any medium, provided you give appropriate credit to the original author(s) and the source, provide a link to the Creative Commons license, and indicate if changes were made.

\section{References}

1. H. Furukawa, N. Ko, Y.B. Go, N. Aratani, S.B. Choi, E. Choi, A.Ö. Yazaydin, R.Q. Snurr, M. O'Keeffe, J. Kim, O.M. Yaghi, Science 329, 424 (2010)

2. O.K. Farha, A.Ö. Yazaydin, I. Eryazici, C.D. Malliakas, B.G. Hauser, M.G. Kanatzidis, S.T. Nguyen, R.Q. Snurr, J.T. Hupp, Nat. Chem. 2, 944 (2010)

3. E. Poirier, A. Dailly, Langmuir 25, 12169 (2009)

4. F.D. Minuto, A. Policicchio, A. Aloise, R.G. Agostino, Int. J. Hydrogen Energ. 40, 14562 (2015)

5. V.P. Ting, A.J. Ramirez-Cuesta, N. Bimbo, J.E. Sharpe, A. Noguera-Diaz, V. Presser, S. Rudic, T.J. Mays, ACS Nano 9, 8249 (2015)

6. S.K. Bhatia, A.L. Myers, Langmuir 22, 1688 (2006)

7. Y.-S. Bae, R.Q. Snurr, Micropor. Mesopor. Mat. 132, 300 (2010)
8. S. Tedds, A. Walton, D.P. Broom, D. Brook, Faraday Discuss. 151, 75 (2011)

9. R. Chahine, T.K. Bose, Hydrogen Energy Prog. XI 1, 1259 (1996)

10. B. Panella, M. Hirscher, S. Roth, Carbon 43, 2209 (2005)

11. M.A. de la Casa-Lillo, F. Lamari-Darkrim, D. Cazorla-Amoros, A. Linares-Solano, J. Phys. Chem. B 106, 10930 (2002)

12. N. Texier-Mandoki, J. Dentzer, T. Piquero, S. Saadallah, P. David, C. Vix-Guterl, Carbon 42, 2744 (2004)

13. M. Schlichtenmayer, M. Hirscher, J. Mat. Chem. 22, 10134 (2012)

14. B. Panella, K. Hönes, U. Müller, N. Trukhan, M. Schubert, H. Pütter, M. Hirscher, Angew. Chem. Int. Ed. 47, 2138 (2008)

15. B. Schmitz, I. Krkljus, E. Leung, H.W. Höffken, U. Müller, M. Hirscher, ChemSusChem 3, 758 (2010)

16. Y.-W. Lee, B.M. Clemens, K.J. Gross, J. Alloy. Compd. 452, 410 (2008)

17. H. Furukawa, M.A. Miller, O.M. Yaghi, J. Mat. Chem. 17, 3197 (2007)

18. D. Denysenko, M. Grzywa, M. Tonigold, B. Streppel, I. Krkljus, M. Hirscher, E. Mugnaioli, U. Kolb, J. Hanss, D. Volkmer, Chem. Eur. J. 17, 1837 (2011)

19. T. Ben, H. Ren, S. Ma, D. Cao, J. Lan, X. Jing, W. Wang, J. Xu, F. Deng, J.M. Simmons, S. Qiu, G. Zhu, Angew. Chem. Int. Ed. 48, 9457 (2009)

20. N. Klein, I. Senkovska, K. Gedrich, U. Stoeck, A. Henschel, U. Mueller, S. Kaskel, Angew. Chem. Int. Ed. 48, 9954 (2009)

21. N. Klein, C. Herzog, M. Sabo, I. Senkovska, J. Getzschmann, S. Paasch, M.R. Lohe, E. Brunner, S. Kaskel, Phys. Chem. Chem. Phys. 12, 11778 (2010)

22. K. Gedrich, I. Senkovska, N. Klein, U. Stoeck, A. Henschel, M.R. Lohe, I.A. Baburin, U. Mueller, S. Kaskel, Angew. Chem. Int. Ed. 49, 8489 (2010)

23. N. Klein, I. Senkovska, I.A. Baburin, R. Grünker, U. Stoeck, M. Schlichtenmayer, B. Streppel, U. Mueller, S. Leoni, M. Hirscher, S. Kaskel, Chem. Eur. J. 17, 13007 (2011)

24. S. Biswas, M. Grzywa, H.P. Nayek, S. Dehnen, I. Senkovska, S. Kaskel, D. Volkmer, Dalton T. 33, 6487 (2009)

25. J.A. Rood, B.C. Noll, K.W. Henderson, Inorg. Chem. 45, 5521 (2006)

26. P. Horcajada, S. Surble, C. Serre, D.Y. Hong, Y.K. Seo, J.S. Chang, J.M. Greneche, I. Margiolaki, G. Ferey, Chem. Comm. 27, 2820 (2007)

27. H.K. Chae, D.Y. Siberio-Perez, J. Kim, Y. Go, M. Eddaoudi, A.J. Matzger, M. O’Keeffe, O.M. Yaghi, Nature 427, 523 (2004)

28. M.R. Lohe, M. Rose, S. Kaskel, Chem. Comm. 40, 6056 (2009)

29. V.K. Peterson, C.M. Brown, Y. Liu, C.J. Kepert, J. Phys. Chem. C 115, 8851 (2011)

30. M.H. Rosnes, M. Opitz, M. Frontzek, W. Lohstroh, J.P. Empbs, P.A. Georgiev, P.D.C. Dietzel, J. Mat. Chem. A 3, 4827 (2015)

31. S. Horike, S. Shimomura, S. Kitagawa, Nat. Chem. 1, 695 (2009)

32. J.A. Mason, J. Oktawiec, M.K. Taylor, M.R. Hudson, J. Rodrigues, J.E. Bachman, M.I. Gonzales, A. Cervellino, A. Guagliardi, C.M. Brown, P.L. Llewellyn, N. Masciocchi, J.R. Long, Nature (2015). doi:10.1038/nature15732 